\title{
Angiosarcoma of the Skin of the Arm after Radical Mastectomy followed by Lymphedema
}

National Cancer Institute

\section{Source}

National Cancer Institute. Angiosarcoma of the Skin of the Arm after Radical

Mastectomy followed by Lymphedema. NCI Thesaurus. Code C40379.

An ang iosarcoma arising from the skin of the arm following radical mastectomy and resulting lymphedema. 